\title{
Effects of preoperative bromocriptine treatment on prolactin-secreting pituitary adenoma surgery
}

\author{
YINGXIAO CAO ${ }^{1}$, FENGJU WANG ${ }^{2}$, ZHENBO LIU $^{2}$ and BAOHUA JIAO ${ }^{1}$ \\ ${ }^{1}$ Department of Neurosurgery, The Second Hospital of Hebei Medical University, Shijiazhuang, Hebei 050000; \\ ${ }^{2}$ Department of Neurosurgery, Xingtai People's Hospital Affiliated to Hebei Medical University, \\ Xingtai, Hebei 054031, P.R. China
}

Received December 7, 2014; Accepted January 11, 2016

DOI: $10.3892 /$ etm.2016.3122

\begin{abstract}
Pituitary adenomas are benign intracranial endocrine tumors, accounting for $\sim 10 \%$ of intracranial tumors. The aim of the present study was to analyze the effects of preoperative treatment with bromocriptine on the surgical treatment and postoperative complications of prolactin-secreting pituitary adenomas (prolactinomas). Data from 102 patients whose prolactinomas were surgically treated between March 2006 and March 2010 were retrospectively reviewed in the present study. The study group included 54 patients who had been treated preoperatively with bromocriptine. The patients were examined by magnetic resonance imaging (MRI) of the head and coronal computed tomography (CT) scanning, after which the pathological diagnosis of prolactinoma was confirmed. A total of 64 patients underwent total resection surgery through the nose and sphenoid sinus, and 25 patients underwent subtotal resection surgery or excision of a large portion of the tumor, leaving only a small quantity of residual tumor or tumor capsule. Patients were followed up for 1-9 months using MRI and measurements of serum prolactin levels. Seven patients were lost to follow-up. The results of the present study demonstrated that patients who were treated with large doses of bromocriptine or used bromocriptine chronically suffered from an increased rate of surgical difficulties and postoperative complications, as compared with the patents who had not been pre-treated with bromocriptine. In conclusion, oral administration of bromocriptine is important in the treatment of prolactinoma tumors. However, large doses or long-term use of bromocriptine may increase difficulties in surgery or postoperative complications, and reduce its ability to treat prolactinonas, as it can lead to hardening of the tumor tissue and capsules, and aggravate pituitary stalk adhesions.
\end{abstract}

Correspondence to: Dr Baohua Jiao, Department of Neurosurgery, The Second Hospital of Hebei Medical University, 215 Hepingxi Road, Shijiazhuang, Hebei 050000, P.R. China E-mail: jiaobh2000@163.com

Key words: pituitary adenomas, resection, bromocriptine, serum prolactin

\section{Introduction}

Pituitary adenomas are a type of benign intracranial endocrine tumor that account for $\sim 10 \%$ of intracranial tumors $(1,2)$, and prolactin-secreting adenomas (prolactinomas) account for $40-60 \%$ of pituitary adenomas (3). The treatment of prolactin-secreting adenomas primarily involves surgery and the administration of drugs such as bromocriptine $(4,5)$. Some patients choose to undergo radiation therapy when surgery and drug therapies have been unsuccessful (6).

The aim of treatment is to eliminate the oppressive effects of pituitary adenomas on normal tissues, and to reduce or control hormone levels to their normal ranges. Clinical treatments include drug therapy, surgery and radiation therapy $(7,8)$. In 2006, the diagnosis and treatment guidelines for pituitary prolactinoma devised at the 9th International Pituitary Congress stated that dopamine agonists are the preferred treatment for patients with prolactinoma (9). In China, the most commonly used treatment is surgery using a nasal transsphenoidal approach supplemented with the oral administration of dopamine agonists, such as bromocriptine. Prolactinomas typically occur in women of childbearing age (20-40 years old). Common symptoms are amenorrhea, lactation and infertility in female patients, and sexual dysfunction in male patients. Prolactinomas are also associated with vision disorders and hypopituitarism resulting from compression by the tumor (10-13).

Drug therapy serves a prominent role in the treatment of prolactinomas; currently, bromocriptine is the most widely used drug clinically; it is as a semi-synthetic lysergic alkaloid bromide that acts as a dopamine agonist. Bromocriptine can reduce tumor size by inhibiting the synthesis and secretion of prolactin, and inhibiting angiogenesis in the surrounding tissue (14). Prolactin levels decrease rapidly following treatment with bromocriptine (7.5-10 $\mathrm{mg} / \mathrm{day})$, and tumors quickly reduce in size or disappear $(15,16)$. Galactorrhea may improve in female patients after 2 weeks of treatment with bromocriptine, and menstruation and ovulation can be recovered after 2 months of treatment (17). In male patients, sexual function can be recovered following several weeks of treatment and typically returns to normal within a year (18). However, the use of bromocriptine has a number of disadvantages; it can cause fibrosis or hardening of tumors, and capsule thickening, which increases the difficulty of surgical tumor removal. In addition, a number of adverse 
reactions can occur in patients, such as nausea, vomiting and orthostatic hypotension. Furthermore, bromocriptine is an expensive drug, requiring long-term administration, and patient compliance is typically poor $(19,20)$.

In the present study, the data from 102 patients who had prolactinomas surgically removed between March 2006 and March 2010 were retrospectively analyzed. The effects of bromocriptine treatment on surgical procedures and postoperative complications were analyzed these patients.

\section{Materials and methods}

Patient information. A total of 102 patients were pathologically diagnosed with prolactinomas, and were surgically treated at Xingtai People's Hospital Affiliated to Hebei Medical University (Xingtai, China) between March 2006 and March 2010. A total of 54 patients (7 males and 47 females; age range, 15-68 years; mean age, 32.7 years), generally those with large adenomas and high prolactin levels, were treated with bromocriptine. The levels of prolactin in the blood of these patients ranged between 12.19 and $736.2 \mathrm{ng} / \mathrm{ml}$ (mean, $139.3 \mathrm{ng} / \mathrm{ml}$. Normal levels in females and males are $<33$ and $<17 \mathrm{ng} / \mathrm{ml}$, respectively. The time of treatment with bromocriptine ranged between 3 weeks and 7 years (mean, 11.8 months), and the treatment doses ranged between 2.5 and $7.5 \mathrm{mg} /$ day. A total of 48 patients (4 males and 44 females; age range, 17-73 years; mean age, 35.4 years) were not treated with bromocriptine because of side effects, such as gastrointestinal reactions and dizziness. The levels of prolactin in the blood ranged between 2.45 and $894.7 \mathrm{ng} / \mathrm{ml}$ (mean, $221 \mathrm{ng} / \mathrm{ml}$ ).

Patients were primarily women of childbearing age, and disease duration ranged between 2 weeks and 20 years (mean, 13.1 months).

Clinical manifestations. Among the female patients, 69 patients experienced menstrual disorders, infertility and lactation, 12 patients experienced a loss of libido, 5 patients experienced acromegaly and 3 patients developed obesity or purple marks on the skin. Among the male patients, 8 patients experienced impotence and sexual dysfunction and 1 patient had gynecomastia. Vision loss or impairment occurred in 43 patients. Elderly patients frequently experienced headaches and loss of vision.

Imaging. All patients were examined by magnetic resonance imaging (MRI; Achieva 3.0TTX; Philips Healthcare, DA Best, The Netherlands) of the head and coronal computed tomography (CT) scanning (SOMATOM Definition AS+ 128; Siemens AG, Munich, Germany). In addition, 12 patients received a CT angiography (CTA) examination (tumor diameter, $>4 \mathrm{~cm}$ surrounding the internal carotid artery) for intraoperative reference. The tumor diameter was $<1 \mathrm{~cm}$ in 56 patients, $1-4 \mathrm{~cm}$ in 34 patients and $>4 \mathrm{~cm}$ in 12 patients. The tumors were invasive in 10 patients, including 9 cases with invasion of the bilateral cavernous sinus, the third ventricle and the bottom of the frontal lobe; the hypothalamus was invaded in 2 cases. Coronal CT scanning revealed 13 patients with sellar floor bone destruction. CTA examination revealed bilateral anterior cerebral artery pressure resulting in the curved forward displacement of bilateral internal carotid arteries to one side, so that they were partly surrounded.

Prolactinoma treatment. All surgical procedures were performed by the same highly qualified surgeon. The prolactin adenoma was resected using a nasal transsphenoidal approach in 89 patients, and using a pterional approach in 13 patients. Prior to surgery, 54 patients had been treated with bromocriptine (2.5-7.5 mg/day) for between 3 weeks and 7 years (mean, 11.8 months). After complete removal of the tumor, a small artificial dura mater (Johnson \& Johnson, New Brunswick, NJ, USA) coated with biological glue (Shunkang Medical Adhesive Co., Ltd., Beijing, China) was placed in the sella floor to prevent cerebrospinal fluid leakage.

Clinical criteria. Postoperative follow-ups were conducted to analyze the effectiveness of the surgery in the treatment of the prolactinomas during the 6 months after surgery. Results for the patients who were treated with bromocriptine were compared with the results obtained without bromocriptine treatment with regard to the efficiency of the surgery, which was classified as cure, remission, progressive or invalid. The criteria for cure were: Prolactin levels returned to normal, menstruation patterns were normal, lactation ceased in females, and the serum testosterone levels (normal range, 1.75-7.81 ng/ml) and sperm count (normal, $>20 \times 10^{7} / \mathrm{ml}$ ) were normal in male patients. Remission criteria were: Prolactinomas returned to normal, menstruation did not recover in females, and the serum testosterone level and sperm count were lower than normal in males. Progression was defined as a prolactinoma reduction of $>80 \%$, and invalid was defined as a prolactinoma reduction of $\leq 80 \%$.

Statistical analysis. The data were analyzed using SPSS version 17.0 statistical software (SPSS, Inc. Chicago, IL, USA). Data are represented as the number of patients. The results were analyzed using the $\chi^{2}$ test. $\mathrm{P}<0.05$ was considered to indicate a statistically significant difference.

\section{Results}

Intraoperative conditions. Total resection surgery was achieved through the nose and sphenoid sinus in 64 patients, and 25 patients underwent subtotal resection or substantial removal of the tumor, leaving a small area of residual tumor or tumor capsule. Craniotomy was conducted in 13 patients, which were cases where the tumors were growing invasively with suprasellar extension and it was observed during surgery that the internal carotid artery was surrounded by optic chiasm that had unclear boundaries with brain tissue. MRI results of the head and coronal CT scans are presented in Fig. 1. The surgical observations of patients with and without bromocriptine treatment are presented in Table I. Significant differences $(\mathrm{P}<0.05)$ in the tumor texture and the frequency of hard and tough capsules and pituitary stalk adhesions were detected between the two groups.

Postoperative complications. Following the surgery, 69 patients developed transient diabetes insipidus, and 7 patients developed permanent diabetes insipidus and required long-term 
Table I. Intraoperative observations.

\begin{tabular}{|c|c|c|c|c|c|c|c|c|c|}
\hline \multirow[b]{2}{*}{ Group } & \multirow[b]{2}{*}{ Patients } & \multicolumn{2}{|c|}{ Texture } & \multirow{2}{*}{$\begin{array}{c}\text { Hard and } \\
\text { tough } \\
\text { capsule }\end{array}$} & \multirow{2}{*}{$\begin{array}{l}\text { Pituitary } \\
\text { stalk } \\
\text { adhesions }\end{array}$} & \multirow{2}{*}{$\begin{array}{l}\text { Rich } \\
\text { blood } \\
\text { supply }\end{array}$} & \multirow{2}{*}{$\begin{array}{l}\text { Tumor } \\
\text { apoplexy }\end{array}$} & \multirow{2}{*}{$\begin{array}{l}\text { Cavernous } \\
\text { sinus } \\
\text { bleeding }\end{array}$} & \multirow{2}{*}{$\begin{array}{l}\text { Cerebrospinal } \\
\text { fluid } \\
\text { leakage }\end{array}$} \\
\hline & & Soft & Hard & & & & & & \\
\hline Bromocriptine & 54 & 19 & 35 & 41 & 29 & 20 & 13 & 11 & 9 \\
\hline Without bromocriptine & 48 & 31 & 17 & 22 & 15 & 14 & 8 & 6 & 5 \\
\hline$\chi^{2}$ & \multicolumn{3}{|c|}{8.788} & 9.744 & 5.223 & 0.708 & 0.853 & 1.133 & 0.838 \\
\hline P-value & \multicolumn{3}{|c|}{0.003} & 0.002 & 0.022 & 0.400 & 0.356 & 0.287 & 0.360 \\
\hline
\end{tabular}

Table II. Postoperative complications.

\begin{tabular}{lcccc}
\hline Group & Patients & Diabetes insipidus & Electrolyte imbalance & Hypopituitarism \\
\hline Bromocriptine & 54 & 45 & 41 & 9 \\
Without bromocriptine & 48 & 31 & 29 & 6 \\
$\chi^{2}$ & & 4.704 & 2.839 & 0.352 \\
P-value & & 0.030 & 0.092 & 0.553 \\
\hline
\end{tabular}

A

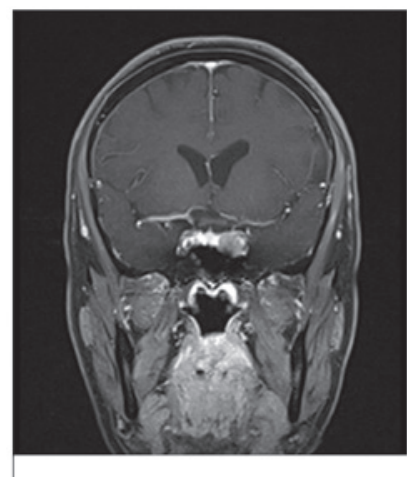

D

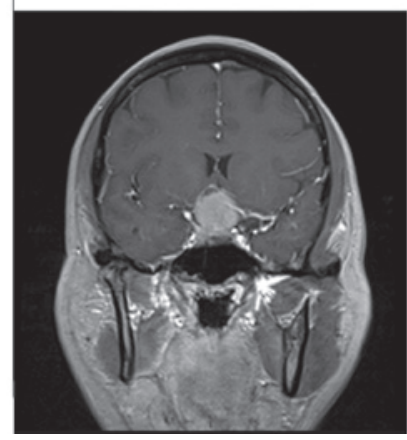

B

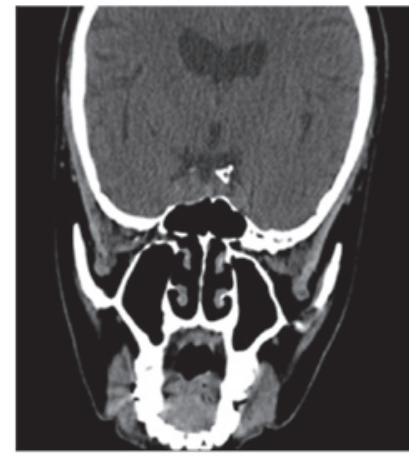

$\mathbf{E}$

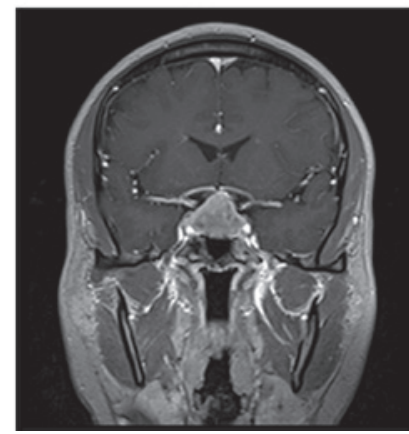

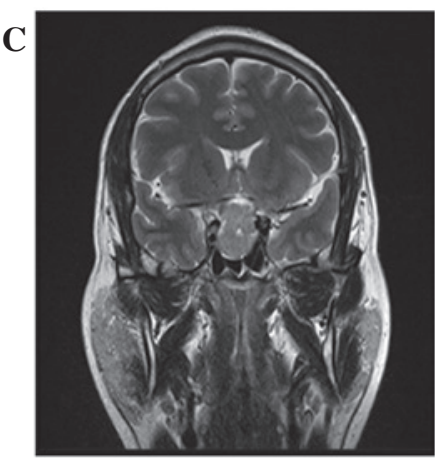

$\mathbf{F}$

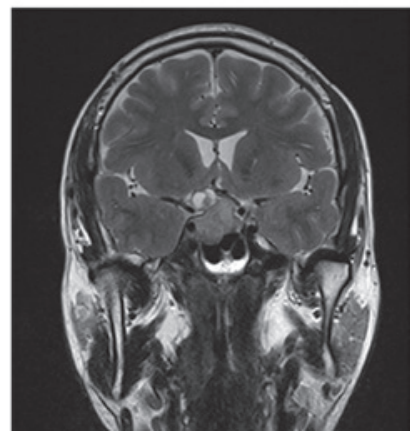

Figure 1. Magnetic resonance imaging of the head and coronal computed tomography scanning used to diagnose prolactinoma. Patients were diagnosed with a pituitary tumor when an abnormal signal was exhibited by the pituitary gland. Tumor volumes are (A) 15x16x20 mm, (B) 14x16x27 mm, (C) 29x36x19 mm, (D) $23 \times 31 \times 26 \mathrm{~mm}$, (E) $22 \times 25 \times 32 \mathrm{~mm}$ and (F) $19 \times 11 \times 22 \mathrm{~mm}$.

(>6 month) oral $1.25 \mathrm{mg}$ desmopressin acetate tablets (Pfizer, Inc., Zurich, Switzerland) 2-3 times/day to control the quantity of urine produced. A total of 64 patients developed hyponatremia, and 7 patients had varying degrees of postoperative cerebrospinal fluid rhinorrhea, the majority of whom were treated within-10 days following conservative treatment with oral bromocriptine. For 2 of the patients with cerebrospinal fluid rhinorrhea, the condition was treated by repair surgery. There were 3 patients who remained unconscious following the craniotomy and were transferred to the intensive care unit for treatment. Intracranial infections with gram-negative bacilli developed in 3 patients and were treated using antibiotics. There were no mortalities. The major complications observed in the patients with and without bromocriptine treatment are presented in Table II.

Follow-up results. Patients were followed up for between 1 and 9 months using MRI examination of the head and 
Table III. Comparison of total cure and remission cases between the two groups.

\begin{tabular}{lcccccc}
\hline Group & Patients & Cure & Remission & Progression & Invalid & Cure and remission, n (\%) \\
\hline Bromocriptine & 51 & 15 & 17 & 14 & 5 & $32(62.7)$ \\
Without bromocriptine & 44 & 23 & 13 & 4 & 4 & $36(81.8)$ \\
$\chi^{2}$ & & 5.144 & 0.157 & & & 4.224 \\
P-value & & 0.023 & 0.692 & & & 0.040 \\
\hline
\end{tabular}

measurement of serum prolactin levels. Seven patients were lost to follow-up, and thus were unable to be assessed. Recurrence of the tumor was observed in 6 patients $(5.9 \%)$, all of which were a result of residual tissue from the tumor remaining following the surgery. A total of 14 patients were treated by $\gamma$-knife following the surgery, and in 6 patients the residual tumor disappeared completely after 6 months, as identified by CT. Menstrual disorders and amenorrhea improved in 38 patients, vision disorders improved in 29 patients and loss of libido improved in 7 patients. The postoperative level of serum prolactin returned to normal (female, $<33 \mathrm{ng} / \mathrm{ml}$, male, $<17 \mathrm{ng} / \mathrm{ml}$ ) in 68 patients; the serum prolactin concentration declined by $>80 \%$ in 18 patients, and by $\leq 80 \%$ in 9 patients. In 19 patients, the levels of prolactin in the blood were $>60 \mathrm{ng} / \mathrm{ml}$ at 1, 3 and 6 months postsurgery, and these patients were treated with bromocriptine (2.5-5.0 mg/day) for adjuvant therapy. In patients who developed hypopituitarism, thyroxine and prednisone replacement therapy was prescribed. The clinical efficacy of bromocriptine in the treatment of prolactin adenomas is presented in Table III. The cure and remission rate in patients treated with bromocriptine was $62.7 \%(32 / 51)$; whereas the cure and remission rate was $81.8 \%(36 / 44)$ in patients without bromocriptine. A significant difference was detected between the two groups $\left(\chi^{2}=4.224 ; \mathrm{P}=0.04\right)$.

\section{Discussion}

Transsphenoidal surgery through the nose and sphenoid sinus is the most common surgical approach for the treatment of pituitary adenomas (21). It is able to entirely remove the tumors, significantly reduce the damage to brain tissue, nerves and blood vessels in during surgery, and results in fewer complications and low mortality, as compared with the traditional transcranial approach $(22,23)$. However, a transcranial surgical approach is required for large pituitary tumors with a hard texture, rich blood supply, dumbbell-shaped tumor growth and expansion outside the sella turcica (24). Postoperative complications include diabetes insipidus, electrolyte imbalance, hypopituitarism and rhinorrhea of the cerebrospinal fluid (25).

The results in the present study demonstrated that there was a significant difference between patients with and without bromocriptine treatment with regards to tumor texture, the hardness and toughness of adenoma capsules, and pituitary stalk adhesions $(\mathrm{P}<0.05)$. These differences between the groups were attributable to the preoperative bromocriptine treatment, which increased the risk of damaging the normal pituitary, pituitary stalk and sellar diaphragm during the surgery. Bromocriptine, therefore, increases the difficulty of surgery and promotes postoperative complications.
Diabetes insipidus is the most common complication following pituitary adenoma surgery, and is caused by damage to the pituitary stalk, posterior pituitary, hypothalamus or the blood supply, which results in an insufficient secretion of antidiuretic hormones (26-28). The results from the present study demonstrated that postoperative complications in the bromocriptine treatment group were more prevalent than those in the group who were not treated with bromocriptine; however, the only post-operative complication that was statistically significant different in prevalence between the two groups was diabetes insipidus.

Cerebrospinal fluid rhinorrhea results from direct intraoperative injury to the sellar diaphragm; this can occur when tumors are large and are excised quickly, causing a rapid reduction of the sellar diaphragm, or when tumors have eroded the sellar diaphragm (29-31). It has also been reported that giant pituitary adenoma, repeat surgery, uneven tumor surface and tough texture may increase the risk of postoperative cerebrospinal fluid rhinorrhea $(32,33)$. The results of the present study demonstrated that 9 patients who were preoperatively prescribed bromocriptine, and 5 patients who were not prescribed bromocriptine, experienced intraoperative cerebrospinal fluid leakage. During the surgery, artificial dura and brain-ear glue were used to repair the sellar floor, and 7 patients experienced varying degrees of cerebrospinal fluid rhinorrhea. By conservative treatment, the majority of patients were cured within 3 to 10 days, and 2 patients were treated by repair surgery using cerebrospinal fluid rhinorrhea endoscopy.

In cases where the size of the prolactinoma is not reduced to its normal size following surgery, the presence of residual tumors should be considered. Residual tumors can be too small to be identified using MRI, or they may become confounded within scars of the sella turcica or the surrounding pituitary tissue. Therefore, if the prolactinoma does not reduce in size, it is recommended that patients be closely followed up by observation of the levels of endocrine indicators and imaging studies (21). If the results from radiological examinations present a clear residual tumor, surgical exploration may be considered again with drug or radiation therapy. The purpose of radiation therapy is to inhibit tumor cell growth and reduce the secretion of hormones from the tumors $(34,35)$. Radiation therapy is primarily used as an adjuvant therapy for patients whose hormone levels have not returned to normal levels, or who have residual tumors detected following surgical treatment.

In the present study, removal of prolactinomas was performed by an experienced neurosurgeon through the nose and sphenoid sinus; the long-term remission rates for such surgery are typically $70-80 \%$ (36). For prolactinomas that 
are confined within the sella turcica, the long-term remission rates can reach $80-90 \%$ (37,38). Follow-up data from these two clinical trials revealed that there was a significant difference between patients with and without bromocriptine treatment with regard to the efficacy following surgical treatment of prolactinomas. These findings were consistent with those reported by Landolt et al (39).

In the present study, treatment with bromocriptine caused difficulties in the removal of the tumors during surgery, as bromocriptine caused adhesion of the pituitary stalk, pituitary tissue, or tumor in the rear of pituitary stalk. Thus, the efficiency of surgery was reduced by bromocriptine; however, the long-term effects of bromocriptine on prolactin adenomas are currently unknown.

In conclusion, the oral administration of bromocriptine is important for the treatment of prolactinoma tumors. However, large doses or chronic use of bromocriptine can increase surgical difficulties and result in postoperative complications due to the hardening of tumor tissues, hardening and toughening of capsules and aggravated adhesions.

\section{References}

1. Hirohata T, Ishii Y and Matsuno A: Treatment of pituitary carcinomas and atypical pituitary adenomas: A review. Neurol Med Chir (Tokyo) 54: 966-973, 2014.

2. Ciric I, Rosenblatt S, Kerr W Jr, Lamarca F, Pierce D and Baumgartner C: Perspective in pituitary adenomas: An end of the century review of tumorigenesis, diagnosis and treatment. Clin Neurosurg 47: 99-111, 2000.

3. Ozgen T, Oruckaptan HH, Ozcan OE and Acikgoz B: Prolactin secreting pituitary adenomas: Analysis of 429 surgically treated patients, effect of adjuvant treatment modalities and review of the literature. Acta Neurochir (Wien) 141: 1287-1294, 1999.

4. Landolt AM, Minder $\mathrm{H}$, Osterwalder $\mathrm{V}$ and Landolt TA: Bromocriptine reduces the size of cells in prolactin-secreting pituitary adenomas. Experientia 39: 625-626, 1983.

5. Laws ER Jr, Thorner MO and Vance ML: Bromocriptine therapy for prolactin-secreting pituitary adenomas. Neurosurg Focus 1: e4, discussion 1p following e6, 1996.

6. Bergström M, Muhr C, Lundberg PO, Bergström K, Gee AD, Fasth KJ and Långström B: Rapid decrease in amino acid metabolism in prolactin-secreting pituitary adenomas after bromocriptine treatment: A PET study. J Comput Assist Tomogr 11: 815-819, 1987.

7. Kim JO, Ma R, Akagami R, McKenzie M, Johnson M, Gete E and Nichol A: Long-term outcomes of fractionated stereotactic radiation therapy for pituitary adenomas at the BC Cancer Agency. Int J Radiat Oncol Biol Phys 87: 528-533, 2013.

8. Elson A, Bovi J, Kaur K, Maas D, Sinson G and Schultz C: Effect of treatment modality on the hypothalamic-pituitary function of patients treated with radiation therapy for pituitary adenomas: Hypothalamic dose and endocrine outcomes. Front Oncol 4: 73, 2014.

9. Casanueva FF, Molitch ME, Schlechte JA, Abs R, Bonert V, Bronstein MD, Brue T, Cappabianca P, Colao A, Fahlbusch R, et al: Guidelines of the Pituitary Society for the diagnosis and management of prolactinomas. Clin Endocrinol (Oxf) 65: 265-273, 2006.

10. Sahoo JP, Kamalanathan S, Parida PK, Pillai V: A giant prolactinoma with nasopharyngeal extension presenting with nasal blockage and epistaxis. BMJ case reports 2015;2015

11. Nakajima T, Tamura T, Kuroki M, Tanaka R and Hayashi H: A case of prolactinoma presenting with CSF rhinorrhea and CSF otorrhea during bromocriptine therapy. No Shinkei Geka 20: 1091-1095, 1992 (In Japanese).

12. Little AS: Repair of cerebrospinal fluid fistula from an invasive skull base prolactinoma using a septal mucosal vascularized flap: Technical case report. J Neurol Surg A Cent Eur Neurosurg 74 (Suppl 1): e50-e53, 2013

13. Sunil B, Reddy A, Bryant N, Young DW and Ashraf AP: Invasive giant prolactinoma presenting as a nasal polyp. J Pediatr 162 435-435, 2013.
14. Webster J: Dopamine agonist therapy in hyperprolactinemia. J Reprod Med 44 (Suppl 12): S1105-S1110, 1999.

15. Acharya SV, Gopal RA, Menon PS, Bandgar TR and Shah NS: Giant prolactinoma and effectiveness of medical management. Endocr Pract 16: 42-46, 2010.

16. Schettini G, Lombardi G, Merola B, Miletto P, Fariello C, Cirillo S, Fusco R and Lancranjan I: Effectiveness of a single injectable dose of bromocriptine long acting in the treatment of macroprolactinomas. J Endocrinol Invest 11: 47-51, 1988.

17. Mroueh AM and Siler-Khodr TM: Bromocryptine therapy in cases of amenorrhea-galactorrhea. Am J Obstet Gynecol 127: 291-298, 1977.

18. Tyson D, ReggiardoD, SklarC and DavidR: Prolactin-secreting macroadenomas in adolescents. Response to bromocriptine therapy. Am J Dis Child 147: 1057-1061, 1993.

19. Palmeri CM, Petiti JP, Sosa Ldel V, Gutiérrez S, De Paul AL, Mukdsi JH and Torres AI: Bromocriptine induces parapoptosis as the main type of cell death responsible for experimental pituitary tumor shrinkage. Toxicol Appl Pharmacol 240: 55-65, 2009.

20. Liuzzi A, Chiodini PG, Dallabonzana D, Oppizzi G and Verde GG: Medical treatment of pituitary adenomas: Effects on tumor growth. J Endocrinol Invest 8: 273-281, 1985.

21. Sharma M, Ambekar S, Sonig A and Nanda A: Factors predicting the development of new onset post-operative Hydrocephalus following trans-sphenoidal surgery for pituitary adenoma. Clin Neurol Neurosurg 115: 1951-1954, 2013.

22. Frank G, Pasquini E and Mazzatenta D: Extended transsphenoidal approach. J Neurosurg 95: 917-918, 2001.

23. Cappabianca P, Cavallo LM, Esposito F, De Divitiis O, Messina A and De Divitiis E: Extended endoscopic endonasal approach to the midline skull base: The evolving role of transsphenoidal surgery. Adv Tech Stand Neurosurg 33: 151-199, 2008

24. Grabenbauer GG, Fietkau R, Buchfelder M, Meyer M, Baumann J, Hensen J, Rummelt V, Fahlbusch R and Sauer R: Hormonally inactive hypophyseal adenomas: The results and late sequelae after surgery and radiotherapy. Strahlenther Onkol 172: 193-197, 1996 (In German).

25. Goyal N, Borkar SA, Agrawal D and Mahapatra AK: Pituitary adenoma presenting with cerebrospinal fluid rhinorrhea as the sole symptom. Neurol India 60: 307-308, 2012.

26. Perrin G, Stevenaert A and Jouanneau E: Technical aspects and surgical strategy for removal of corticotroph pituitary adenoma. Neurochirurgie 48: 186-214, 2002 (In French).

27. Gondim JA, Almeida JP, de Albuquerque LA, Gomes E, Schops M and Mota JI: Endoscopic endonasal transsphenoidal surgery in elderly patients with pituitary adenomas. J Neurosurg 123: 31-38, 2015.

28. Berkmann S, Schlaffer S, Nimsky C, Fahlbusch R and Buchfelder M: Intraoperative high-field MRI for transsphenoidal reoperations of nonfunctioning pituitary adenoma. J Neurosurg 121: 1166-1175, 2014.

29. Mehta GU, Bakhtian KD and Oldfield EH: Effect of primary empty sella syndrome on pituitary surgery for Cushing's disease. J Neurosurg 121: 518-526, 2014.

30. Berker M, Hazer DB, Yucel T, Gurlek A, Cila A, Aldur M and Onerci M: Complications of endoscopic surgery of the pituitary adenomas: Analysis of 570 patients and review of the literature. Pituitary 15: 288-300, 2012.

31. Cho JM, Ahn JY, Chang JH and Kim SH: Prevention of cerebrospinal fluid rhinorrhea after transsphenoidal surgery by collagen fleece coated with fibrin sealant without autologous tissue graft or postoperative lumbar drainage. Neurosurgery 68: 130-136, 2011

32. Lehman NL, Horoupian DS and Harsh GR IV: Synchronous subarachnoid drop metastases from a pituitary adenoma with multiple recurrences. Case report. J Neu rosurg 98: 1120-1123, 2003.

33. Kim EH, Ku CR, Lee EJ and Kim SH: Extracapsular en bloc resection in pituitary adenoma surgery. Pituitary 18: 397-404, 2015.

34. Tanaka S, Link MJ, Brown PD, Stafford SL, Young WF Jr and Pollock BE: Gamma knife radiosurgery for patients with prolactin-secreting pituitary adenomas. World Neurosurg 74: $147-152,2010$.

35. Wollesen $F$ and Bendsen BB: Effect rates of different modalities for treatment of prolactin adenomas. Am J Med 78: $114-122,1985$ 
36. Dai WD, Liu WH and Zhang DL: One hemodialysis patient with headache, blurred vision and hypotension induced by pituitary prolactinoma. Chin Med J (Engl) 125: 2787-2789, 2012.

37. Domingue ME, Devuyst F, Alexopoulou O, Corvilain B and Maiter D: Outcome of prolactinoma after pregnancy and lactation: A study on 73 patients. Clin Endocrinol (Oxf) 80: 642-648, 2014
38. Qu X, Wang M, Wang G, Han T, Mou C, Han L, Jiang M, Qu Y, Zhang M, Pang Q and Xu G: Surgical outcomes and prognostic factors of transsphenoidal surgery for prolactinoma in men: A single-center experience with 87 consecutive cases. Eur J Endocrinol 164: 499-504, 2011.

39. Landolt AM, Keller PJ, Froesch ER and Mueller J: Bromocriptine: Does it jeopardise the result of later surgery for prolactinomas? Lancet 2: 657-658, 1982. 